\title{
CLINICAL AND PHYSIOLOGICAL ASPECTS OF A CASE OF OBESITY, POLYCYTHEMIA AND ALVEOLAR HYPOVENTILATION
}

\author{
By J. HOWLAND AUCHINCLOSS, Jr., ELLEN COOK, AND ATTILIO D. RENZETTI \\ (From the Department of Medicine, State University of New York, Upstate Medical Center \\ at Syracuse, $N . Y$.)
}

(Submitted for publication March 31, 1955; accepted June 22, 1955 )

The occurrence of arterial hypoxia with polycythemia usually results from some known type of pulmonary disease or from an abnormal communication between the right and left sides of the circulation. Although arterial oxygen unsaturation has been observed in patients with polycythemia vera $(1-4)$, it is usually of only mild degree. Recently, Newman, Feltman, and Devlin (5) found polycythemia and a severe degree of arterial hypoxia in two patients who did not have evidence of any previously described form of lung disease. These authors postulated that polycythemia vera by its effects on the lung or on the respiratory center could give rise to oxygen unsaturation of arterial blood. They also suggested that in some patients polycythemia is secondary to respiratory center disease of undetermined etiology.

It is the purpose of the present report to present the clinical and physiological findings in an obese young man with polycythemia and arterial oxygen unsaturation.

\section{CLINICAL REPORT}

$C$. D., a thirty-year old white man was admitted to the hospital on January 8, 1954 complaining of shortness of breath and ankle swelling. He had weighed more than 200 pounds for at least 13 years. In 1942 he worked as a furnace feeder in an aluminum plant for six months. He first noted a non-productive cough in 1950 and since then had experienced an increased frequency of respiratory infections. In March, 1952, an elevated hematocrit was observed, and by October, 1952 he had to stop work because of dyspnea and ankle edema. In the six months before entering the hospital these symptoms increased, and he developed orthopnea.

Physical examination revealed an alert, cyanotic, slightly orthopneic man who weighed 290 pounds and was 67 inches in height. A few rales were heard at the right posterior lung base. The heart was in gallop rhythm, and the pulmonic second sound was accentuated. Mild edema of the abdominal wall and marked edema of the lower extremities was present.
The significant laboratory findings were as follows: red blood cells 6.77 million per cu. mm.; hemoglobin 20 gm. per cent; hematocrit 69 per cent; white blood cells 6,000 per cu. $\mathrm{mm}$. with a normal differential count and normal cellular morphology; platelets 150,000 per cu. $\mathrm{mm}$. The bone marrow showed hyperplasia of the erythroid series, and reticulocytes were 1 per cent of the red blood cells. The blood uric acid was $9.6 \mathrm{mg}$. per cent. The urinary $17-$ ketosteroid excretion was $8 \mathrm{mg}$. in twenty-four hours (normal). X-ray of the chest showed cardiac enlargement and enlargement of the pulmonary vessels. Angiocardiography showed filling of the cardiac chambers in normal sequence. The sella turcica appeared normal by X-ray. An electrocardiogram showed evidence of right ventricular hypertrophy.

Treatment consisted of bed rest, digitalis, sodium and caloric restriction, mercurials and, beginning on the sixth day, repeated phlebotomies. By the end of seventeen days after his date of entry into the hospital a total of five liters of blood had been removed. The patient lost twenty-four pounds in the first five days and an additional thirty pounds before leaving the hospital. He became free of dyspnea and edema and less cyanotic. A chest X-ray taken ten days after admission showed marked diminution in the degree of vascular engorgement, and right ventricular enlargement became apparent. He was discharged on February 9, 1954, to continue on the treatment regimen described above.

His status was re-evaluated on April 4, 1954, when his weight and physical findings were the same as they had been at the time of discharge from the hospital. Red blood cell, white blood cell and platelet counts were normal, and the chest $\mathrm{X}$-ray showed further diminution of vascular markings. Neurological, psychometric and electroencephalographic examinations failed to reveal organic brain disease. However, a slight cerebral dysrhythmia without a focal pattern was present on the electroencephalogram. Intermittent treatment in a chest respirator for several days and advice to breathe deeply did not change his clinical status, and he left the hospital after two weeks of observation.

He entered the hospital again on October 4, 1954, at which time there was no change in the clinical or laboratory findings except for a ten-pound weight gain. During his hospital stay of three weeks, a twenty-pound weight loss was effected by more rigid caloric and sodium restriction. 


\section{METHODS}

Measurements of lung volumes, maximum ventilatory capacity, ventilation and gas exchange at rest were made according to the methods of Baldwin, Cournand, and Richards (6). Arterial blood was sampled from an indwelling needle in the brachial artery. Oxygen content and capacity and carbon dioxide content were determined by the method of Van Slyke and Neill (7). Whole blood $\mathrm{pH}$ was determined at $37^{\circ}$ on a Cambridge Research Model pH meter. Expired air was analyzed on the Scholander gas analyzer (8). The oxygen tension of arterial blood was determined by the technique of Riley, Proemmel, and Franke (9). The carbon dioxide tension of arterial blood was obtained by use of the Van Slyke and Sendroy line charts (10). Analysis of the ventilation-perfusion relationships and the diffusion characteristics of the lung at rest was made according to the methods of Riley, Cournand, and Donald (11). The maximal diffusing capacity of the lung was measured by the techniques described by Riley, Shepard, Cohn, Carroll, and Armstrong (12). Cardiac catheterization, sampling of mixed venous blood and determination of cardiac output was carried out as described by Cournand, Baldwin, and Himmelstein (13). During the sec-

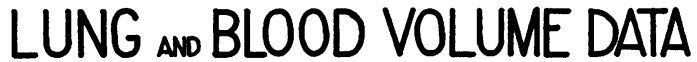

\section{C.D., 30, W.M. POLYCYTHEMIA-CAUSE UNKNOWN}

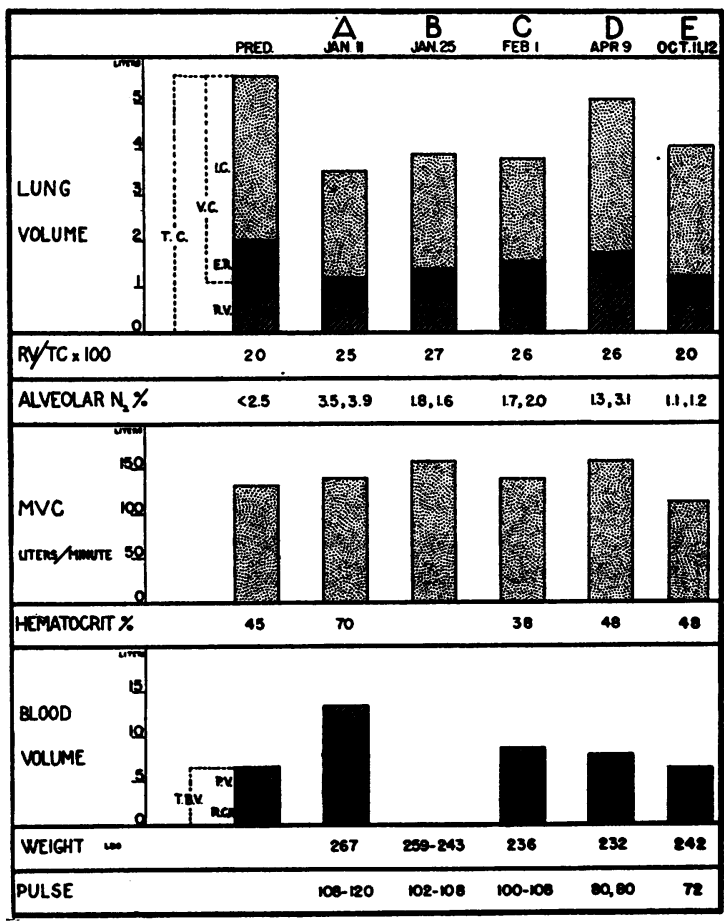

Figure 1

Periods : A, before venesection; $\mathrm{B}$, while venesection in progress; C, D, and $\mathrm{E}$, after venesection completed.

ond cardiac catheterization the procedure for studying a suspected case of congenital heart disease was done according to the method described by the latter authors. Blood pressure in the pulmonary and brachial arteries and in the right ventricle was recorded by the use of calibrated electromanometers. Plasma volume was determined by the T-1824 dye method as described by Gibson, Evans, and Evelyn $(14,15)$.

The symbols and units used in presenting the observed, assumed and derived values are those recommended by a group of pulmonary physiologists (16) and specifically modified by Riley and Cournand (17).

SYMBOLS

Values for lung volumes, maximum ventilatory capacity and minute ventilation are expressed as liters or liters per minute B.T.P.S. Other symbols and units are as follows:

$\mathrm{CaO}_{2}$

$\mathrm{Cap}_{\mathrm{z}}$

$\mathrm{Caco}_{2}$

$\mathrm{D}_{2}$

$\mathrm{FIO}_{2}$

f

$\mathrm{P}_{\mathrm{AO}}$

$\mathrm{PaO}_{2}$

$\mathrm{Pe}^{\mathrm{AcO}} 2$

$\overline{\mathrm{Paco}}$

$\overline{\mathrm{P}_{\mathrm{O}}}$

PIo,

Q்va/Q்t $\times 100$

R

Sa

Sce

$\mathrm{S} \overline{\mathbf{v}}$

$V^{e}$

$\mathrm{VT}^{\circ}$

$\mathrm{VD}^{\circ} / \mathrm{VT}^{\circ}$

VE

$\dot{\mathbf{V}}_{\mathbf{O}_{2}}$
$\mathrm{O}_{2}$ concentration of arterial blood, in vols. per cent.

$\mathrm{O}_{2}$ capacity of arterial blood, in vols. per cent.

$\mathrm{CO}_{2}$ content of arterial blood, in vols. per cent.

Diffusing capacity of the lungs.

Fractional oxygen concentration of inspired gas.

Respiratory rate in breaths per minute.

"Effective" alveolar $\mathrm{Po}_{2}$ in $\mathrm{mm} . \mathrm{Hg}$.

Arterial $\mathrm{Po}_{2}$ in $\mathrm{mm}$. $\mathrm{Hg}$.

"Effective" alveolar $\mathrm{P}_{\mathrm{CO}_{2}}$ in $\mathrm{mm}$. $\mathrm{Hg}$. Its equality with $\mathrm{PaCO}_{2}$ is assumed except where Q்a/Q்t exceeds 20 per cent, in which case it is calculated from the venous admixture equation and the physiological $\mathrm{CO}_{2}$ dissociation curve of the patient.

Arterial $\mathrm{P}_{\mathrm{CO}_{2}}$ in $\mathrm{mm}$. $\mathrm{Hg}$.

Mean partial pressure of oxygen in the pulmonary capillaries.

Inspired gas $\mathrm{P}_{\mathrm{O}_{2}}$, in $\mathrm{mm}$. $\mathrm{Hg}$ B.T.P.S.

Ratio of venous admixture to total blood flow, expressed as per cent.

The $\mathrm{CO}_{2}-\mathrm{O}_{2}$ exchange ratio or respiratory quotient.

The oxygen saturation of arterial blood.

The oxygen saturation of "effective" capillary blood.

The oxygen saturation of mixed venous blood.

Physiological dead space, corrected for apparatus dead space in ml. B.T.P.S.

Tidal volume, corrected for apparatus dead space in ml. B.T.P.S.

Dead space-tidal volume fractional ratio.

Minute volume of expired gas in liters per minute B.T.P.S.

$\mathrm{O}_{2}$ consumption in ml. per minute S.T.P.D. (standard temperature and pressure, dry). 


\section{VENTILATORY DATA DURING AIR BREATHING STUDIES}

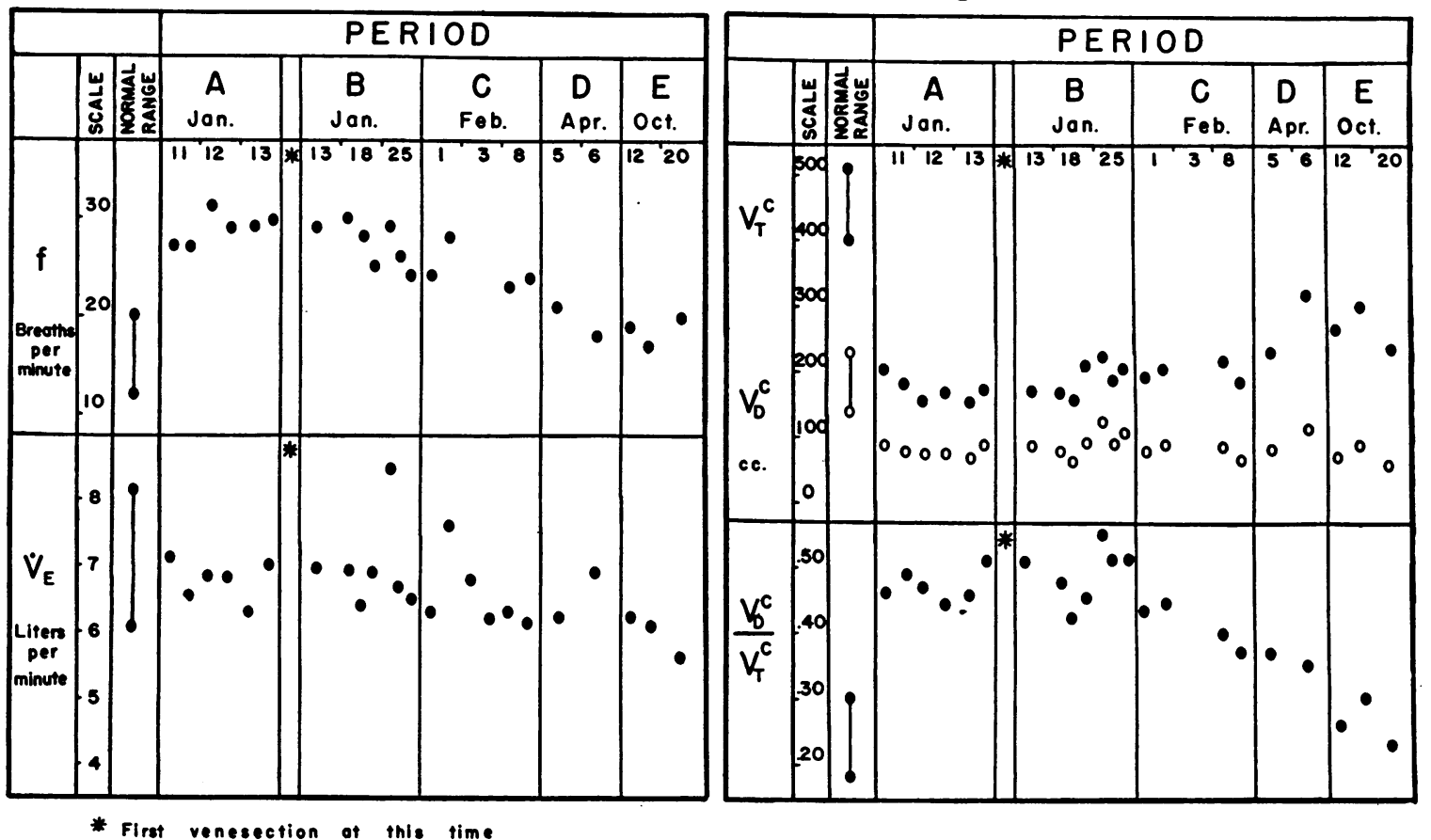

Figure 2

Refer to text for definition of symbols.

\section{RESULTS}

The results of physiologic study are indicated in Figures 1 to 3 and Tables I to III. Shortly after admission to the hospital, during a period (period A) when rapid weight reduction was occurring, there was a considerable reduction in the total lung capacity which resulted chiefly from a reduction of the vital capacity. Despite the somewhat elevated alveolar nitrogen concentration after the patient had breathed 99 per cent oxygen for seven minutes, it was evident from the reduced absolute value for residual lung volume, the normal maximum ventilatory capacity and the normal spirogram that obstructive emphysema was not present. The estimated total blood volume was almost two times greater than the predicted value and this increase was entirely due to erythrocytosis. Although total minute ventilation was normal, the tidal volume was much reduced. The arterial oxygen tension and oxyhemoglobin per cent saturation were extremely low and carbon dioxide tension was greatly increased. Following the inhalation of 99 per cent oxygen (Table I), a further reduction in tidal volume occurred with a consequent rise in arterial blood carbon dioxide tension, while arterial oxygen saturation increased to 89 per cent. Further study in this initial period (A) revealed that the physiological dead space and the diffusing capacity of the lung at rest were normal $(18,19)$ but that the percentage of venous admixture was greatly increased. The percentage venous admixture in this instance was calculated according to the equation of Riley, Cournand, and Donald (11) employing the data obtained from cardiac catheterization and the inhalation of 99 per cent oxygen. Studies of the hemodynamics of the right heart and pulmonary circulation revealed elevation of the right ventricular end diastolic pressure and a marked degree of hypertension in the pulmonary artery which did not change immediately after the removal of 600 ml. of blood.

During the next seventeen days (period B), a total of 5 liters of blood was removed so that the 


\section{ARTERIAL BLOOD DATA DURING AIR BREATHING STUDIES}

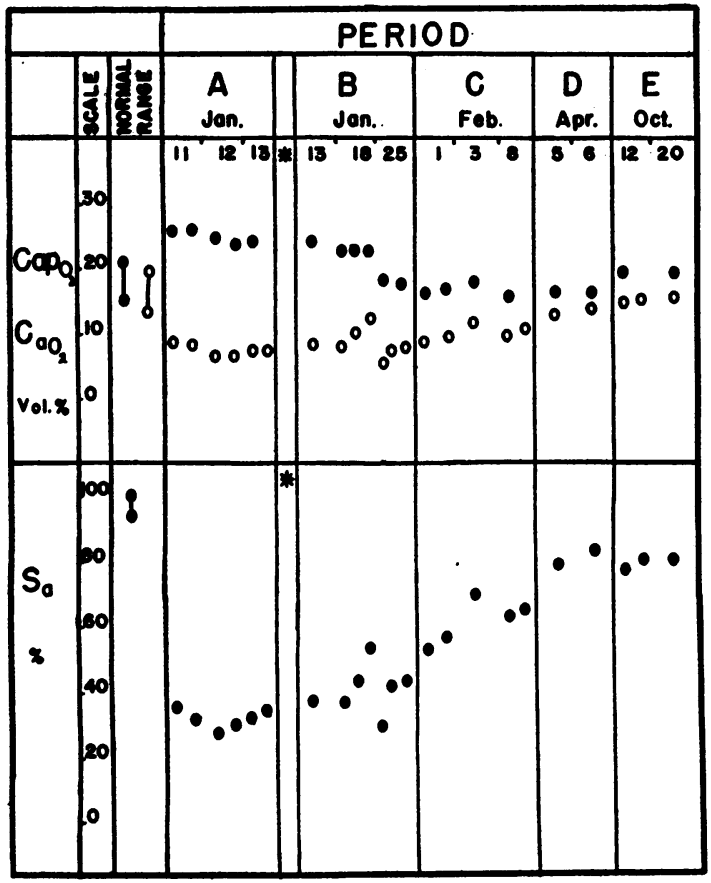

* First venesection of this time

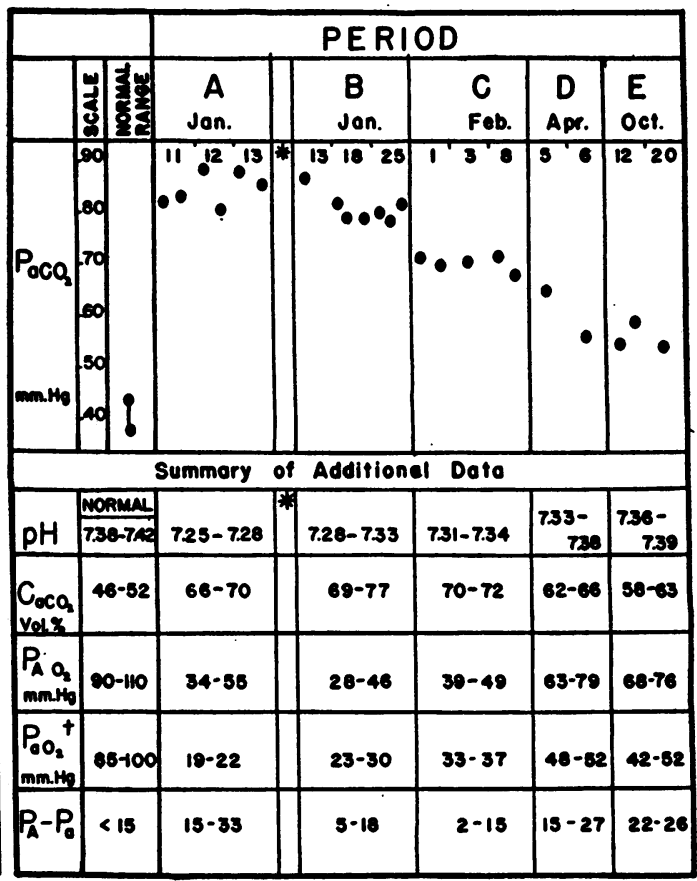

$t$ Not corrected for pH chonge

FIGURE 3

Refer to text for definition of symbols.

total blood volume and red cell mass returned to normal. Throughout the ten months of observation sodium and caloric restriction were maintained, and digitalis administration was continued. Repeated study at intervals (periods C, D, and E) showed no significant changes in the measurements of lung volumes and maximum ventilatory capacity, and erythrocytosis did not recur. With the progressive increase in tidal volume, the values for arterial oxygen saturation and tension and carbon dioxide tension returned toward normal, but even after ten months the tidal volume was reduced, and a moderate degree of hypercapnia and arterial hypoxia was present. It is evident from Table I that alveolar ventilation could be much improved by the use of inspiratory positive pressure breathing. The percentage of venous admixture after recovery from failure came to be within normal limits during exercise (20) but was considerably elevated in the last period (E) of study. The maximal diffusing capacity was measured at three and ten months after the ini- tial studies and was found to be normal (20). A second cardiac catheterization (Table III) was done two months after the first one. Although the pressure in the pulmonary artery was lower than before, it was still considerably elevated. In addition, the end diastolic pressure in the right ventricle was still above normal. When 99 per cent oxygen was inhaled during the course of this catheterization, full saturation of the arterial blood with oxygen occurred, but the pressure in the pulmonary artery fell only slightly. Neither an abnormal intracardiac communication nor a valvular stenosis could be demonstrated at this second catheterization.

\section{DISCUSSION}

The observations reported here do not permit a classification of this patient's illness into any previously described clinical or physiologic syndrome. The physiologic findings differ from the patterns of dysfunction which have been found 
TABLE I

Data obtained during the use of 100 per cent $O_{2}$ and the Bennett IPPB*

\begin{tabular}{|c|c|c|c|c|}
\hline \multirow{2}{*}{$\begin{array}{l}\text { Period } \\
\text { Date } \\
\text { Condition }\end{array}$} & \multicolumn{2}{|c|}{$\begin{array}{c}A \\
1-12-54\end{array}$} & \multicolumn{2}{|c|}{$\begin{array}{c}\text { C } \\
2-8-54\end{array}$} \\
\hline & Rest & Rest & Rest & Rest, IPPB \\
\hline FIq & .2086 & .9939 & .2086 & .2086 \\
\hline Pise & 108 & 108 & 104 & 80 \\
\hline$f$ & 29 & 32 & 24 & 31 \\
\hline$V_{E}$ & 6.8 & 5.3 & 6.1 & 9.2 \\
\hline$V^{c}$ & 169 & 101 & 185 & 232 \\
\hline $\mathrm{Poco}_{2}$ & 80 & 91 & 67 & 52 \\
\hline$P O a_{2}$ & 39 & $>400$ & 45 & 84 \\
\hline $\mathrm{PaO}_{2}$ & 19 & 65 & 33 & 58 \\
\hline $\mathrm{Pe}_{\mathrm{AO}_{2}}-\mathrm{PaO}_{2}$ & 20 & & 12 & 26 \\
\hline$V_{D}^{e} / V_{T}^{e}$ & .44 & .46 & .37 & .38 \\
\hline Sa & 30 & 89 & 65 & 87 \\
\hline
\end{tabular}

* In both instances eampling was done after 15 minutes. Values for $\mathrm{PeAa}_{2}$ and $\mathrm{PaO}_{2}$ are corrected to $\mathrm{pH} 7.40$.

TABLE II

Two level oxygen studies

\begin{tabular}{|c|c|c|c|c|c|c|c|c|c|c|c|c|c|c|c|c|c|c|}
\hline PER & Status & $s$ Date & $P_{0}$ & $\dot{\mathbf{V}}_{\mathbf{E}}$ & $\dot{V}_{\mathrm{O}_{2}}$ & $R$ & $f$ & & & & $\begin{array}{r}Q \\
\times 10\end{array}$ & & & & & & & $i S$ \\
\hline $\mathbf{A}$ & Reet & $1-13-54$ & 148 & 6.3 & 327 & .73 & 29 & 88 & $?$ & .46 & $44-67^{*}$ & $>21$ & 32 & $(17-22)$ & 17 & 15 & $<15$ & $(15-25)$ \\
\hline \multirow[t]{2}{*}{ C } & Reet & $2-8.54$ & 237 & 5.3 & 351 & .59 & 20 & 73 & (0) & .40 & 20 & & 109 & 109 & 73 & 36 & 14 & (27) \\
\hline & & & 145 & 6.1 & 336 & .64 & 24 & 67 & (0) & .37 & 20 & 24 & 45 & 35 & 33 & 12 & 14 & (27) \\
\hline \multirow[t]{2}{*}{$\bar{D}$} & Reet & $4-5.54$ & 174 & 6.1 & 353 & .64 & 21 & 68 & 5 & .35 & 33 & & 80 & 80 & 51 & 29 & 17 & (30) \\
\hline & & & 148 & 6.2 & 317 & .72 & 21 & 65 & 3 & .37 & 33 & 19 & 63 & 59 & 44 & 19 & 17 & (30) \\
\hline \multirow[t]{2}{*}{$\bar{D}$} & Exercise & $4-7-54$ & 173 & 22.5 & 1488 & .78 & 29 & 67 & $(0)$ & .25 & 8 & & 86 & 84 & 68 & 18 & 27 & (40) \\
\hline & $\begin{array}{l}3.1 \mathrm{mph} \\
\text { at } 6^{\circ}\end{array}$ & & 120 & 29.7 & 1531 & .92 & 27 & 59 & (0) & .24 & 8 & 57 & 53 & 33 & 32 & 21 & 27 & (40) \\
\hline \multirow[t]{2}{*}{ D } & Exercise & $4-12-54$ & 173 & 20.2 & 1616 & .75 & 23 & 76 & $(0)$ & .24 & 4 & & 70 & 57 & 54 & 16 & 31 & (40) \\
\hline & $\begin{array}{l}3.1 \mathrm{mph} \\
\text { tt } 6\end{array}$ & & 121 & 30.5 & 1543. & .96 & 23 & 57 & $(0)$ & .22 & 4 & 50 & 58 & 32 & 32 & 26 & 31 & (40) \\
\hline \multirow[t]{2}{*}{$\bar{E}$} & Reot & $10-12: 54$ & 171 & 6.3 & 330 & .73 & 17 & 60 & 2 & .33 & 32 & & 94 & 89 & 54 & 40 & 32 & (30) \\
\hline & & & 145 & 6.1 & 329 & .72 & 17 & 59 & 2 & .30 & 32 & 10 & 69 & 51 & 40 & 29 & 32 & (30) \\
\hline \multirow[t]{2}{*}{$E$} & Reot & $10-21-54$ & 148 & 5.6 & 289 & .71 & 19 & 56 & 1 & .23 & 32 & & 73 & 72 & 49 & 24 & 16 & (30) \\
\hline & & & 121 & 6.4 & 302 & .85 & 19 & 49 & 2 & .14 & 32 & 19 & 64 & 61 & 45 & 19 & 16 & (30) \\
\hline \multirow[t]{2}{*}{$\bar{E}$} & Exercise & $10-15-54$ & 171 & 25.4 & 1767 & .76 & 29 & 65 & (0) & .22 & 18 & & 86 & 81 & 56 & 30 & 30 & (40) \\
\hline & $\begin{array}{l}3.1 \mathrm{mph} \\
\text { at } 6^{\circ}\end{array}$ & & 119 & 32.3 & 1699 & .93 & 27 & 57 & (0) & .20 & 18 & 57 & 56 & 32 & 29 & 27 & 30 & (40) \\
\hline
\end{tabular}

* Calculated from respoase to $100 \% \mathrm{O}_{2}$ inhalation on preceding day (See Text).

Assumed values are placed in parentheses 
TABLE III

Catheterization data before and after therapy

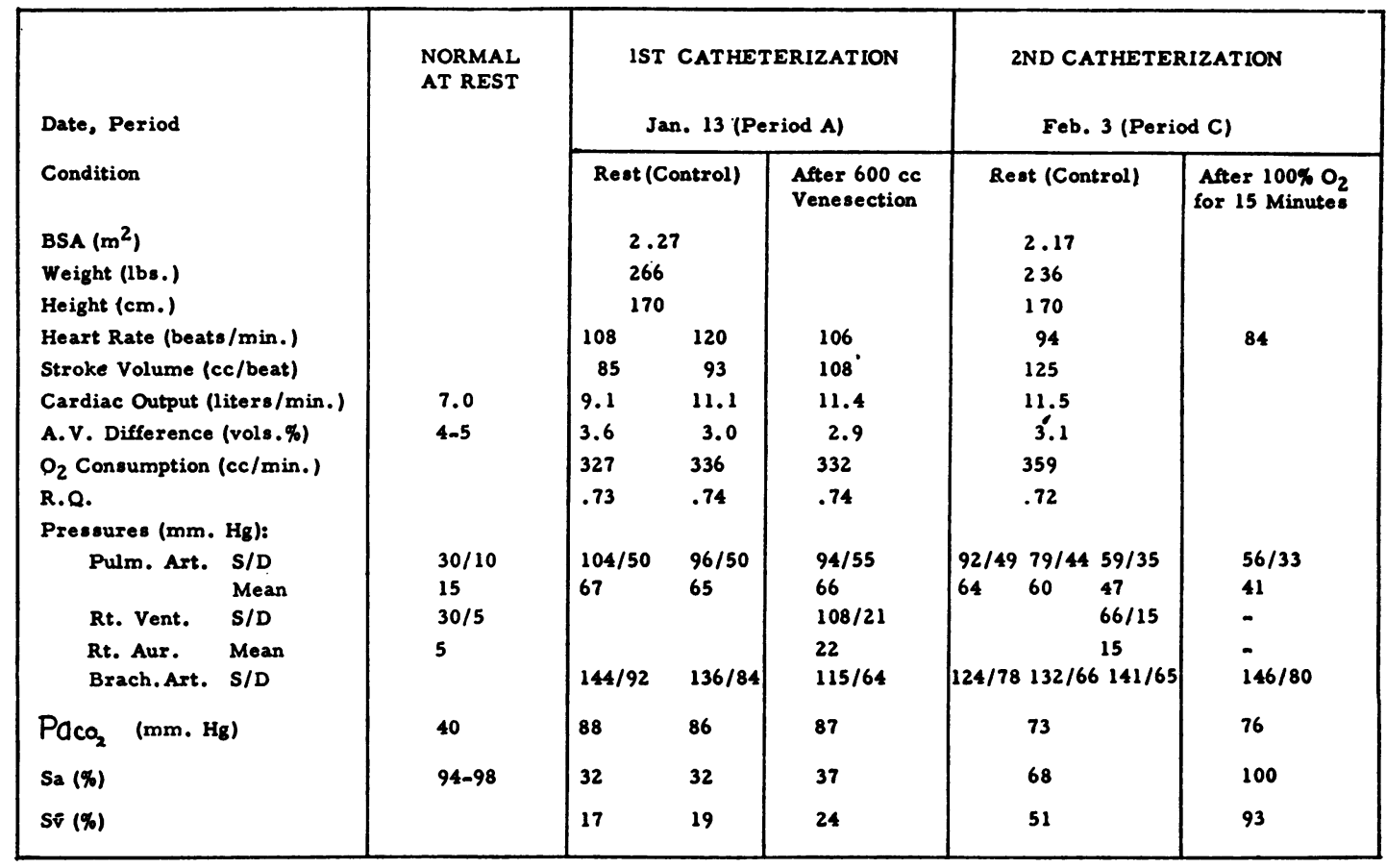

to characterize those groups of pulmonary diseases that have been described under the heading of pulmonary fibrosis (21), alveolar-capillary block (22), or pulmonary emphysema (23). The observations are similar in most respects to those made by Newman, Feltman, and Devlin (5) in two individuals, and it seems likely that the pathogenesis of the illness is the same in the two instances. However, the failure of the maximum ventilatory capacity to return to normal after treatment in one of their cases contrasts to the ever normal value in this individual and suggests that their patient may have had an additional ventilatory defect.

The severe degree of alveolar hypoventilation demonstrated by this patient can probably account for all of the other physiologic abnormalities which were observed. Thus, arterial hypoxia and carbon dioxide retention would be expected as the immediate consequence of such a defect. With continued hypercapnia and the secondary rise in buffer base the respiratory center would become less sensitive to carbon dioxide, and hence the hypoventilation would tend to be perpetuated. It seems likely that the very small tidal volume which characterized this hypoventilation would leave areas of the lung whose blood circulation was maintained without adequate ventilation and in this manner account for the elevated percentage of venous admixture that was found. It would not be unexpected that the persistence of such hypoxia over a long period would lead to polycythemia. Finally, from the report of similar findings in a patient with diffuse disease of the central nervous system but without intrinsic pulmonary disease (24), it seems possible that long standing hypoxia with its consequent polycythemia may have been sufficient cause for pulmonary hypertension and right heart failure of the high output type to occur.

It is evident from the data presented that no abnormal right to left circulatory shunt existed. Although the percentage of venous admixture was extremely high initially and full saturation of the arterial blood on 99 per cent oxygen breathing was not achieved, it seems likely that this resulted from the marked pulmonary congestion. Neither exploratory cardiac catheterization nor angiocardiography revealed a shunt, and in subsequent study the percentage venous admixture was much reduced and during exercise approached normal values. In addition, increased venous admixture 
would offer no explanation for the $\mathrm{CO}_{2}$ retention observed $(11,25)$.

Whether or not the sequence of events was that which has been postulated above, an initiating mechanism for the alveolar hypoventilation was not discovered. It has been suggested (5) that polycythemia vera by a direct effect on the respiratory center might cause hypoventilation, but in this case no confirmatory manifestations of polycythemia vera, e.g., splenomegaly, leucocytosis or thrombocytosis were present. It also seems unlikely that primary damage to the respiratory center with consequent loss of carbon dioxide sensitivity was present since no other signs of organic brain disease could be found and since arterial carbon dioxide tension returned toward normal following treatment. Since the hypoventilation was characterized by a marked reduction of tidal volume, it is possible that it resulted from an overabundance of inspiratory-inhibitory impulses to the respiratory center from stretch receptors either in the lungs or elsewhere in the ventilatory apparatus. If disease of the pulmonary parenchyma accounted for such a disturbance, it was not of sufficient extent to result in detectable roentgenological abnormality. In the absence of such abnormality, the reduction in total lung capacity can best be related to extreme obesity, cardiac enlargement and a long standing pulmonary vascular disturbance. The patient's exposure to fumes from aluminum furnaces was of only six months' duration; this fact, together with the lack of radiologic abnormality would seem to rule out the presence of a pneumoconiosis of the type described by Shaver and Riddell (26).

It appears possible, however, that the obesity either by a mechanical effect leading to an increase in the work of breathing or else by a reflex effect might give rise to a diminished tidal volume. With respect to mechanical effects it is known that the addition of resistance to the airway (27) can induce progressively decreasing tidal volume with carbon dioxide retention. This patient had no increase in airway resistance as evidenced by the normal maximum ventilatory capacity and spirograms. Undoubtedly there are other factors, both mechanical and reflex, such as the retractive forces and stretch receptors of the chest bellows which could modify tidal volume, but satisfactory methods of studying these in patients have not been developed. Therefore, the importance of the obesity in this instance cannot be evaluated.

Severe pulmonary hypertension at rest was present even after all clinical evidence of right heart failure had disappeared. The elevation of cardiac output was not of sufficient magnitude to cause pulmonary hypertension in a normal individual (28). Since correction of the arterial oxygen unsaturation did not relieve the pulmonary hypertension, it was probably not maintained by hypoxia alone. Thus it seems probable that the pulmonary hypertension was at least in part due to an anatomic reduction in the capacity of the pulmonary vascular bed. It is likely that such anatomic reduction was in the arteriolar or arterial branches since the normal maximum diffusing capacity suggests that the area of the pulmonary capillary surface was normal (12). It is impossible to determine with certainty whether pulmonary arterial disease resulted from long standing hypoxia or was primary. However, if primary pulmonary vascular disease was present, it was not of the type described by Dresdale, Schultz, and Michtom (29), for their patients, unlike this one, had a reduced cardiac output and normal arterial oxygen saturation.

\section{SUM MARY}

An obese young man with cyanosis, dyspnea and edema was found to have erythrocytosis and right ventricular hypertrophy but no evidence of disease of the lungs or chest wall or of the central nervous system. Physiologic study revealed the presence of marked arterial hypoxia and hypercapnia and severe alveolar hypoventilation which was characterized by a marked reduction in tidal volume without an increase in respiratory frequency sufficient to maintain normal alveolar ventilation. Marked pulmonary arterial hypertension and increased cardiac output were also present. There was no evidence that these findings were initiated by an abnormal cardiac or vascular communication. Treatment with bed rest, low salt diet, mercurials, digitalis, and phlebotomy was associated with disappearance of dyspnea and edema. When studied after ten months of such treatment arterial hypoxia and hypercapnia and alveolar hypoventilation were still present al- 
though to a lesser degree than at the time of initial observation.

All of the physiologic abnormalities have been attributed to the alveolar hypoventilation, but an initiating mechanism for the alveolar hypoventilation was not discovered.

\section{Addendum}

Since this paper was submitted for publication two additional reports have appeared in which very similar physiologic derangements are described $(30,31)$.

\section{ACKNOWLEDGMENT}

We wish to thank Miss Elizabeth Coulter and Mrs. Mary Burdick for their technical assistance.

\section{REFERENCES}

1. Harrop, G. A., Jr., and Heath, E., Pulmonary gas diffusion in polycythemia vera. J. Clin. Invest., 1927, 4, 53.

2. Wasserman, L. R., Dobson, R. L., and Lawrence, J. H., Blood oxygen studies in patients with polycythemia and in normal subjects. J. Clin. Invest., 1949, 28, 60.

3. Stewart, H. J., Wheeler, C. H., and Crane, N. F., The circulatory adjustments in polycythemia vera. Am. Heart J., 1941, 21, 511.

4. Cassels, D. E., and Morse, M., The arterial blood gases, the oxygen dissociation curve, and the acidbase balance in polycythemia vera. J. Clin. Invest., 1953, 32, 52.

5. Newman, W., Feltman, J. A., and Devlin, B., Pulmonary function studies in polycythemia vera. Results in five probable cases. Am. J. Med., 1951, 11, 706.

6. Baldwin, E. de F., Cournand, A., and Richards, D. W., Jr., Pulmonary insufficiency. I: Physiological classification, clinical methods of analysis, standard values in normal subjects. Medicine, 1948, 27, 243.

7. Van Slyke, D. D., and Neill, J. M., The determination of gases in blood and other solutions by vacuum extraction and manometric measurements. I. J. Biol. Chem., 1924, 61, 523.

8. Scholander, P. F., Analyzer for accurate estimation of respiratory gases in one-half cubic centimeter samples. J. Biol. Chem., 1947, 167, 235.

9. Riley, R. L., Proemmel, D. D., and Franke, R. E., A direct method for determination of oxygen and carbon dioxide tensions in blood. J. Biol. Chem., $1945,161,621$.

10. Van' Slyke, D. D., and Sendroy, J., Jr., Studies of gas and electrolyte equilibria in blood. XV. Line charts for graphic calculations by the Hen-
derson-Hasselbalch equation, and for calculating plasma carbon dioxide content from whole blood content. J. Biol. Chem., 1928, 79, 781.

11. Riley, R. L., Cournand, A., and Donald, K. W., Analysis of factors affecting partial pressures of oxygen and carbon dioxide in gas and blood of lungs: Methods. J. Applied Physiol., 1951, 4, 102.

12. Riley, R. L., Shepard, R. H., Cohn, J. E., Carroll, D. G., and Armstrong, B. W., Maximal diffusing capacity of the lungs. J. Applied Physiol., 1954, 6, 573.

13. Cournand, A., Baldwin, J. S., and Himmelstein, A., Cardiac Catheterization in Congenital Heart Disease; A Clinical and Physiological Study in Infants and Children. New York, The Commonwealth Fund, 1949, Chap. 1, p. 6.

14. Gibson, J. G., 2nd, and Evans, W. A., Jr., Clinical studies of the blood volume. I. Clinical application of a method employing the AZO dye "Evans Blue" and the spectrophotometer. J. Clin. Invest., 1937, 16, 301.

15. Gibson, J. G., 2nd, and Evelyn, K. A., Clinical studies of the blood volume. IV. Adaptation of the method to the photoelectric microcolorimeter. J. Clin. Invest., 1938, 17, 153.

16. Standardization of definitions and symbols in repiratory physiology. Federation Proc., 1950, 9, 602.

17. Riley, R. L., and Cournand, A., Analysis of factors affecting partial pressures of oxygen and carbon dioxide in gas and blood of lungs: Theory. $J$. Applied Physiol., 1951, 4, 77.

18. Fishman, A. P., Studies in man of the volume of the respiratory dead space and the composition of the alveolar gas. J. Clin. Invest., 1954, 33, 469.

19. Carroll, D., Cohn, J. E., and Riley, R. L., Pulmonary function in mitral valvular disease: Distribution and diffusion characteristics in resting patients. J. Clin. Invest., 1953, 32, 510.

20. Cohn, J. E., Carroll, D. G., Armstrong, B. W., Shepard, R. H., and Riley, R. L., Maximal diffusing capacity of the lung in normal male subjects of different ages. J. Applied Physiol., 1954, 6, 588.

21. Baldwin, E. de F., Cournand, A., and Richards, D. W., Jr., Pulmonary insufficiency. II. A study of thirty-nine cases of pulmonary fibrosis. Medicine, 1949, 28, 1.

22. Austrian, R., McClement, J. H., Renzetti, A. D., Jr., Donald, K. W., Riley, R. L., and Cournand, A., Clinical and physiological features of some types of pulmonary diseases with impairment of alveolarcapillary diffusion. The syndrome of "alveolarcapillary block." Am. J. Med., 1951, 11, 667.

23. Baldwin, E. de F., Cournand, A., and Richards, D. W., Jr., Pulmonary insufficiency. III. A study of 122 cases of chronic pulmonary emphysema. Medicine, 1949, 28, 201.

24. Feltman, J. A., Newman, W., Schwartz, A., Stone, D. J., and Lovelock, F. J., Cardiac failure sec- 
ondary to ineffective bellows action of the chest cage. J. Clin. Invest., 1952, 31, 762.

25. Morse, M., and Cassels, D. E., Arterial blood gases and acid-base balance in cyanotic congenital heart disease. J. Clin. Invest., 1953, 32, 837.

26. Shaver, C. G., and Riddell, A. R., Lung changes associated with the manufacture of alumina abrasives. J. Indust. Hyg. \& Toxicol., 1947, 29, 145.

27. Davies, H. W., Haldane, J. S., and Priestly, J. G., The response to respiratory resistance. $J$. Physiol., 1919, 53, 60.

28. Riley, R. L., Himmelstein, A., Motley, H. L., Weiner, H. M., and Cournand, A., Studies of the pulmonary circulation at rest and during exercise in normal individuals and in patients with chronic pulmonary disease. Am. J. Physiol., 1948, 152, 372.

29. Dresdale, D. T., Schultz, M., and Michtom, R. J., Primary pulmonary hypertension. I. Clinical and hemodynamic study. Am. J. Med., 1951, 11, 686.

30. Comroe, J. H., Forster, R. E., II, Dubois, A. B., Briscoe, W. A., and Carlson, E., The Lung; Clinical Physiology and Pulmonary Function Tests, Chicago, The Year Book Publishers, 1955, p. 142.

31. Sieker, H. O., Estes, E. H., Jr., Kelser, G. A., and McIntosh, H. D., A cardiopulmonary syndrome associated with extreme obesity. J. Clin. Invest., 1955, 34, 916. 